\title{
Management of osteoporotic vertebral fractures
}

This article was published in the following Dove Press journal:

International Journal of General Medicine

24 June 2010

Number of times this article has been viewed

\section{Yannis Dionyssiotis}

Rhodes General Hospital, Rhodes, Greece
Correspondence:Yannis Dionyssiotis Rehabilitation Department, Rhodes General Hospital, Agioi Apostoloi, 85100 , Rhodes, Dodecanese, Greece Tel +302241080395

Fax +302241066410

Email yannis_dionyssiotis@hotmail.com
Abstract: Osteoporotic vertebral fractures are associated with considerable reduction of quality of life, morbidity, and mortality. The management of patients with vertebral fractures should include treatment for osteoporosis and measures to reduce pain and improve mobility. This article provides information for management and rehabilitation of vertebral fractures based on clinical experience and literature.

Keywords: vertebral fracture, quality of life, rehabilitation, osteoporosis

\section{Introduction}

Health consequences from osteoporotic fractures in women include disability and increased mortality. As a result vertebral fractures have a negative impact on the quality of life and their presence is linked with cardiopulmonary morbidities, depression and death. $^{1-6}$

The most important target is to prevent these fractures, but if a fracture exists the focus shifts to rehabilitation and prevention of the next fracture. Lindsay et al confirmed that women who develop a vertebral fracture are at substantial risk for additional fracture within the next year. ${ }^{7}$

Musculoskeletal pain, common in patients with osteoporotic vertebral fractures, is one of the most frequent symptoms for which medical assistance is sought. Osteoporosis represents one of the main causes of back pain in postmenopausal women. ${ }^{8}$ Although, in the same population, nonosteoporotic vertebral deformities are seen as often as osteoporotic ones, and they are also a main cause of back pain. In women up to 60 years back pain was found to be mostly due to degenerative disorders of the spine. ${ }^{9}$

Clinical or subclinical vertebral fractures are a common cause of back pain. Vertebral fractures cause acute pain in the back in the acute phase of the fracture and chronic pain resulting from the associated skeletal deformity, joint incongruity, and tension on muscles and tendons, ${ }^{10}$ leading to disability. It is surprising that most of these patients do not receive an antiosteoporotic treatment. ${ }^{11}$

\section{Targeted osteoporotic drug treatment}

Pharmacologic treatment should be prescribed for those who have sustained vertebral fractures. ${ }^{11}$ In fact in a retrospective study only $15 \%$ of medical records indicated that fracture patients had been prescribed antiosteoporotic medications within one year after discharge from hospital. ${ }^{12,13}$ 
The therapeutic effect of bisphosphonates on back pain has rarely been reported on in patients with vertebral fractures. ${ }^{14}$ Nevitt et al have reported the efficacy of long-term treatment with alendronate in elderly osteoporotic patients for reducing the burden of activity limitation and bed disability caused by back pain. ${ }^{14,15} \mathrm{~A}$ valuable drug in the rehabilitation process of elderly patients suffering from back pain due to osteoporotic vertebral collapse seems to be intravenous pamidronate. ${ }^{14,16}$

Armingeat et al in their controlled trial of intravenous pamidronate comparing placebo for pain relief in recent osteoporotic vertebral compression fractures found a rapid, marked, and sustained analgesic effect of pamidronate for reducing acute back pain due to recent osteoporotic vertebral fracture, without any significant safety concerns. ${ }^{17}$

In a review article Ulivieri stated that treating patients with antiresorptive and anabolic agents reduces the risk of new or worsening back pain, particularly with teriparatide therapy. ${ }^{18}$ In line with this paper Nevitt et al in a metaanalysis, concluded that teriparatide had a reduced risk of new or worsening back pain compared to patients randomized to placebo, hormone replacement therapy, or alendronate. ${ }^{19}$ In a retrospective analysis, Lindsay et al reported that the presence of one or more vertebral fractures resulted in a five-fold increase in risk for sustaining a subsequent vertebral fracture. ${ }^{20}$ Therapeutic options can reduce the number of new vertebral compression fractures by $40 \%-60 \%$ within the first year in individuals with a fracture. ${ }^{21}$

\section{Calcium, vitamin D, and vitamin D analogues $^{21}$}

Pooled data comparing vitamin $\mathrm{D}$ alone with placebo or no treatment showed no statistically significant effect on vertebral fracture or deformity.22 Vitamin D (including 25-hydroxy vitamin $\mathrm{D}$ ) with calcium was no more effective than calcium alone on vertebral fracture. Evidence has shown that vitamin D alone was less effective than calcium for the prevention of vertebral fracture or deformity. There was no evidence of a statistically significant preventive effect on clinical vertebral fractures from the administration of vitamin $\mathrm{D}$ and calcium and vitamin $\mathrm{D}$ plus calcium versus placebo or no treatment. In participants with osteoporosis no statistically significant effect of alfacalcidol (1-alpha-hydroxy vitamin D3) compared with vitamin $\mathrm{D}$ and calcium on people with new vertebral deformities was found. Calcitriol (1,25 dihydroxy vitamin D3), and additional supplementation with calcitriol in people with osteoporosis who were already taking calcium had no statistically significant effect on new vertebral deformity. No statisti- cally significant effect on the number of people developing new vertebral deformities receiving calcitriol plus vitamin D and calcium versus vitamin D and calcium was found. Overall, there was no statistically significant effect on the incidence of vertebral deformities with calcitriol versus calcium. When calcitriol was compared with vitamin D in people with pre-existing osteoporosis no statistically significant effect was seen for vertebral deformities.

\section{Other interventions}

Back pain in the majority of these patients is treated with prolonged bed-rest, local and systemic analgesia, and bracing. ${ }^{23}$ Thereby, the incidence of a vertebral fracture should be followed by a limited period of bed rest, to avoid the hazards of deconditioning, accelerated bone loss, deep venous thrombosis, pneumonia, decubitus ulcers, disorientation, and depression. ${ }^{24,25}$

The extension of bed-rest in these patients results in increase of bone loss (identified by increase of hydroxyproline excretion) and muscle weakness and joint stiffness. Another interesting aspect is that most osteoporotic vertebral fractures happen in high bone turnover patients, and in these patients postfracture immobilization is an additional risk factor of increased bone loss. ${ }^{26}$ Nasal salmon calcitonin in a daily dose of $200 \mathrm{IU}$ has an equivalent analgesic effect to $100 \mathrm{IU}$ of injectable salmon calcitonin..$^{21,27,28}$ The analgesic efficacy of nasal calcitonin was tested in 32 men and 68 postmenopausal women with a mean age of 76 and 71 years respectively, who, within the previous 5 days, had sustained a nontraumatic vertebral fracture which had been confirmed radiographically and clinically. ${ }^{13}$ The patients were hospitalized for a period of 28 days and were randomly assigned to receive either $200 \mathrm{IU}$ of nasal salmon calcitonin or a matching nasal placebo spray. In addition patients were permitted to take paracetamol as a rescue analgesic up to 6 tablets of $500 \mathrm{mg}$ daily. Treatment was initiated after baseline measurements on day 0. Pain evaluation was performed daily using a 10-degree visual analog scale (VAS) $(0=$ no pain, $10=$ agonizing pain $)$. Pain was tested during different locomotor functions eg, bed rest, sitting, standing, and walking. In our experience if a patient records a pain above 7 (in the VAS scale) he is not capable of attempting the recommended locomotor function. In turn, a rating of pain less than 7 suggests that the patient does not require nursing and bed rest and that he is able to begin physiotherapy. After the completion of 28 days of follow-up it was found that pain was reduced dramatically in the group receiving calcitonin $(P<0.001)$. The analgesic effect of nasal calcitonin was negatively associated with the number of 
Table I Differences in values of visual analog scale (VAS) and personal isometric force: force (F)/weight (W) in abdominals and extensors muscles (F/W abdominals and F/W extensors, respectively), after 6 months wearing Spinomed orthosis. (F: force in Newton, $\mathrm{W}$ : weight in $\mathrm{Kg}$ ) measured with ISO-RACK device (Digimax, MechaTronic, Germany)

\begin{tabular}{|c|c|c|c|}
\hline \multicolumn{4}{|c|}{ Patients in the beginning of the study ( 1 ) vs patients wearing Spinomed for 6 months (2) } \\
\hline Variables & $\begin{array}{l}\text { Patients starting wearing Spinomed } \\
\mathbf{n}=10 \\
\text { mean } \pm \text { sd }\end{array}$ & $\begin{array}{l}\text { Patients wearing Spinomed for } 6 \text { months } \\
\mathrm{n}=10 \\
\text { mean } \pm \mathrm{sd}\end{array}$ & $P$-value \\
\hline $\begin{array}{l}\text { VAS (difference } \\
\text { VAS I-VAS 2) }\end{array}$ & $65 \pm 16.5$ & $41 \pm 17$ & 0.001 \\
\hline $\begin{array}{l}\text { F/W abdominals } \\
\text { (difference } \\
\text { F/Wabd I - F/Wabd 2) (N) }\end{array}$ & $|3| . \mid \pm 53.7$ & $197.8 \pm 82.7$ & 0.005 \\
\hline $\begin{array}{l}\text { F/W extensors } \\
\text { (difference } \\
\text { F/W ext I - F/W ext 2) (N) }\end{array}$ & $197.6 \pm 48$ & $246.3 \pm 59.5$ & 0.003 \\
\hline
\end{tabular}

paracetamol tablets consumed. The VAS pain rating showed that most patients gradually gained full mobility after the first week of calcitonin treatment. The number of patients who remained bedridden was significantly higher in the placebo group at all time points than in the calcitonin group. ${ }^{13}$

Spinal compression fracture and pain can produce an imbalance between the use of back extensors (the major trunk supportive muscles) and flexors. To decrease painful contractions of the erector spinae muscles, one needs to decrease the load over the anterior aspect of the spinal column and vertebral bodies.

Bracing is used in acute nonsurgical management, whereas spinal orthoses relieve the pain and promote the healing process by stabilizing the spine. It should be noted that the latter reduces the load applied on the anterior column and vertebral body by restraining any attempt of forward flexion. Even though there is a lack of specific studies comparing various types of orthoses, it is widely accepted that all spine orthoses, whether made of cloth, metal, or plastic, and whether rigid or flexible, use a three-point pressure system. ${ }^{24,25}$

The most broadly used types of spinal orthoses in Greece $^{24}$ are: a) the TLSO type that provides support to the thoracolumbosacral spine by making it adopt an anatomically correct position (Knight-Taylor, Jewett, CASH, or Cruciform Anterior Sternal, Boston, MA), b) the posture training support (PTS) type, which is a device that has shoulder straps joining above the waist at the back, where a pouch holds small weights, ${ }^{29} \mathrm{c}$ ) Spinomed ${ }^{\circledR}$, the new 'bracing' philosophy, based on biofeedback theory ${ }^{30}$ and d) Osteomed ${ }^{\circledR}$, which is based upon the gate control theory of pain. ${ }^{31,32}$

Kaplan et al pointed out that orthotic devices impose a risk of reduction in muscular strength. Their controlled pilot study with a 4-week observation period demonstrated that the strength of the back extensors was reduced to below the initial value in $40 \%$ of female patients wearing a stable orthotic device. ${ }^{33}$ On the contrary we published recently preliminary results of women with established osteoporosis and/or an angle of kyphosis more than 55 degrees wearing Spinomed orthosis for at least 2 hours/day for 6 months showing that Spinomed significantly decreased back pain $(P=0.001)$ (evaluation was performed using visual analog scale at the beginning and 6 months follow-up of the examination) and increased personal isometric trunk muscle strength, (Table 1 and Figure 1). ${ }^{34}$

Pfeifer et al also reported the effectiveness of Spinomed for stabilizing osteoporotic vertebral fractures. In their study the use of Spinomed was associated with a significant increase in trunk muscle strength, most likely because of increased muscular activity while wearing the orthosis. ${ }^{30}$

A program of physical therapy is necessary and helps prevent deformity by strengthening antigravity muscles and promoting postural retraining. Breathing exercises promote thoracic expansion and improve the heavily degraded pulmonary function found in patients with spinal osteoporotic

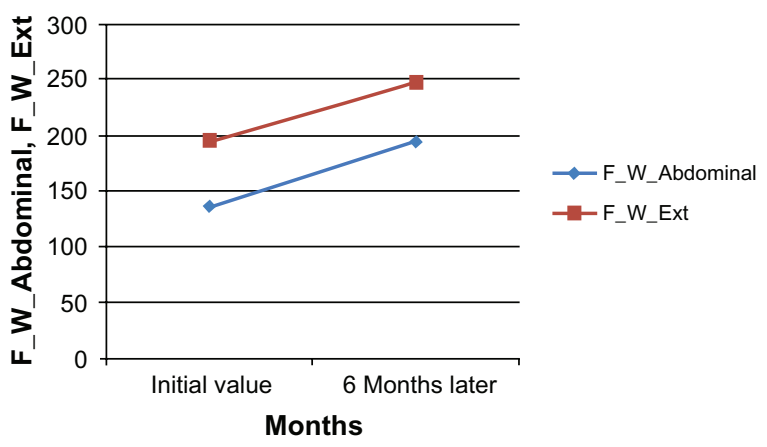

Figure I Schematic presentation of values in personal isometric force in Newton $(\mathrm{N})$ : Force (F)/Weight $(\mathrm{W})$ in abdominals and extensor muscles (F/W abdominals and F/W ext, respectively), after 6 months wearing Spinomed orthosis (F: force in Newton, W: weight in $\mathrm{Kg}$ ). 
fractures. ${ }^{35}$ Instruction on the proper method of lifting things, as well as how to use a walker or a cane properly, could be beneficial and thus is strongly recommended. ${ }^{24,35}$ Patients with fractures could subject themselves to low-intensity exercise and gentle strengthening programs (eg, Tai Chi and hydrotherapy) and are strongly recommended to avoid high impact exercise or movements, so that they avoid suffering new vertebral fractures. ${ }^{29}$ Forward bending of the spine or flexion exercises, especially in combination with twisting, should be avoided. ${ }^{24,29}$ According to Bassey, this includes several old favorite exercises which are now considered outdated, namely straight-leg toe touches and sit ups (or crunches) for strengthening the abdominal muscles. ${ }^{36}$ Sinaki and Mikkelsen reported that the latter are associated with a dramatically increased rate of vertebral fracture in osteoporotic women $(89 \%$ compared to $16 \%$ of those who did extension exercises). ${ }^{37}$ As the acute fracture pain subsides, a walking program can begin with gentle strengthening exercises focusing on spinal extensor muscles. ${ }^{38}$ A carefully supervised rehabilitation program should be started after 3 to 4 months, to strengthen the spinal extensor and abdominal muscles more aggressively. ${ }^{24,39}$

\section{Vertebroplasty and kyphoplasty}

These procedures are different in several aspects. Vertebroplasty mainly involves the application of polymethylmethacrylate (PMMA) to the fracture. This procedure is considered to be very successful in the stabilization of fractured osteoporotic vertebral body and in pain relief. ${ }^{40}$ A possible alternative is to inject calcium phosphate cement into a vertebral fracture, while in kyphoplasty a balloon is inserted to create space in the fractured vertebra, to restore its height and shape, before the balloch it is removed and the cement is delivered to the resulting space. Percutaneous vertebroplasty obtains early pain relief and improves the integrity of the osteoporotic vertebral body. ${ }^{41}$ On the other hand the mini-surgical intervention may cause serious complications to patients with recent fractures, such as paraplegia, ${ }^{42}$ and the occurrence of a new vertebral body fracture, and possible cardiopulmonary events. ${ }^{43}$ Two studies in 2009 concerning the efficacy of vertebroplasty may signal a different approach for this procedure. ${ }^{44,45}$ In the first study 48 patients with one or two painful osteoporotic vertebral fractures were randomized in a multicenter, double-blind, placebo-controlled trial (vertebroplasty vs a sham procedure). The authors found no significant advantage for vertebroplasty at any time point during follow-up between groups with respect to pain at night and at rest, physical functioning, quality of life, and perceived improvement. Another study in 131 patients, with one to three painful osteoporotic vertebral fractures, randomized either in vertebroplasty or a sham procedure found similar results. ${ }^{45}$ The authors noted a trend toward a higher rate of clinically meaningful improvement in pain in the vertebroplasty group but improved disability and pain scores were noted immediately following both procedures.

On the other hand a randomized controlled trial (Fracture Reduction Evaluation [FREE] trial) which took place at 21 sites in eight countries and included 149 patients assigned to balloon kyphoplasty showed that in patients with acute, painful, vertebral fractures, balloon kyphoplasty improved quality of life, function, mobility, and pain more rapidly than did nonsurgical management, with significant differences in improvement between the groups at 1 month. ${ }^{46}$

\section{Disclosure}

No benefits in any form have been received or will be received from a commercial party related directly or indirectly to the subject of this article.

\section{References}

1. Papaioannou A, Watts NB, Kendler DL, Yuen CK, Adachi JD, Ferko N. Diagnosis and management of vertebral fractures in elderly adults. $\mathrm{Am}$ J Med. 2002;113:220-228.

2. Yamaguchi T, Sugimoto T, Yamauchi M, Matsumori Y, Tsutsumi M, Chihara K. Multiple vertebral fractures are associated with refractory reflux esophagitis in postmenopausal women. J Bone Miner Metab. 2005;23:36-40.

3. Tosi LL, Bouxsein ML, Johnell O. Commentary on the AAOS position statement: recommendations for enhancing the care for patients with fragility fractures. Tech Orthop. 2004;19:121-125.

4. Cooper C, Atkinson EJ, Jacobsen SJ, O'Fallon WM, Melton LJ III. Population based study of survival after osteoporotic fractures. Am J Epidemiol. 1993;137:1001-1005.

5. Ismail AA, Cockerill W, Cooper C, et al. Prevalent vertebral deformity predicts incident hip though not distal forearm fracture: results from the European Prospective Osteoporosis Study. Osteoporos Int. 2001; 12:85-90.

6. Gold DT. Osteoporosis and quality of life: psychosocial outcomes and interventions for individual patients. Clin Geriatr Med. 2003;19: 271-280.

7. Lindsay R, Silverman SL, Cooper C, et al. Risk of new vertebral fracture in the year following a fracture. JAMA. 2001;285:320-323.

8. Gehlbach SH, Bigelow C, Heimisdottir M, May S, Walker M, Kirkwood JR. Recognition of vertebral fracture in a clinical setting. Osteoporos Int. 2000;11:577-582.

9. Molsberger A, Jensen KU, Muller U, Winkelmann W, Wehling P. Chronic pain syndromes in orthopedics. Typical types, follow-up and patient characteristics. Z Orthop Ihre Grenzgeb. 1989;127:695-700.

10. Francis RM, Aspray TJ, Hide G, Sutcliffe AM, Wilkinson P. Back pain in osteoporotic vertebral fractures. Osteoporos Int. 2008;19:895-903.

11. Bouxsein ML, Kaufman J, Tosi L, Cummings S, Lane J, Johnell O. Recommendations for optimal care of the fragility fracture patient to reduce the risk of future fracture. J Am Acad Orthop Surg. 2004;12: 385-395.

12. Panneman MJ, Lips P, Sen SS, Herings RM. Undertreatment with antiosteoporotic drugs after hospitalization for fracture. Osteoporos Int. 2004;15:120-124. 
13. Lyritis GP, Trovas G. Analgesic effects of calcitonin. Bone. 2002; 30 Suppl 5:71S-74S.

14. Iwamoto J, Takeda T, Ichimura S, Uzawa M. Comparative effects of treatment with etidronate and alendronate on bone resorption, back pain, and activities of daily living in elderly women with vertebral fractures. Keio J Med. 2003;52:230-235.

15. Nevitt MC, Thompson DE, Black DM, et al. Effect of alendronate on limited activity days and bed-disability days caused by back pain in postmenopausal women with existing vertebral fractures. Fracture Intervention Trial Research Group. Arch Intern Med. 2000;160:77-85.

16. Gangji V, Appelboom T. Analgesic effect of intravenous pamidronate on chronic back pain due to osteoporotic vertebral fractures. Clin Rheumatol. 1999;18:266-267.

17. Armingeat T, Brondino R, Pham T, Legré V, Lafforgue P. Intravenous pamidronate for pain relief in recent osteoporotic vertebral compression fracture: a randomized double-blind controlled study. Osteoporos Int. 2006;17:1659-1665.

18. Ulivieri FM. Back pain treatment in post-menopausal osteoporosis with vertebral fractures. Aging Clin Exp Res. 2007;19 Suppl 3:21-23.

19. Nevitt MC, Chen P, Dore RK, et al. Reduced risk of back pain following teriparatide treatment: a meta-analysis. Osteoporos Int. 2006;17: $273-280$.

20. Lindsay R, Silverman SL, Cooper C, et al. Risk of new vertebral fracture in the year following a fracture. JAMA. 2001;285:320-323.

21. Lyritis GP, Tsakalakos N, Magiasis B, Karachalios T, Yiatzides A, Tsekoura M. Analgesic effect of salmon calcitonin in osteoporotic vertebral fractures: a double-blind placebo-controlled clinical study. Calcif Tissue Int. 1991;49:369-372.

22. Avenell A, Gillespie WJ, Gillespie LD, O'Connell D. Vitamin D and vitamin D analogues for preventing fractures associated with involutional and post-menopausal osteoporosis. Cochrane Database of Syst Rev. 2009;CD000227.

23. Lukert BP. Vertebral compression fractures: how to manage pain, avoiding disability. Geriatrics. 1994;49:22-26.

24. Dionyssiotis Y, Dontas IA, Economopoulos D, Lyritis GP. Rehabilitation after falls and fractures. J Musculoskelet Neuronal Interact. 2008; 8:244-250.

25. Mazanec DJ, Podichetty VK, Mompoint A, Potnis A. Vertebral compression fractures: manage aggressively to prevent sequelae. Cleve Clin J Med. 2003;70:147-156.

26. Lyritis GP, Mayasis B, Tsakalakos N, et al. The natural history of the osteoporotic vertebral fracture. Clin Rheumatol. 1989;8 Suppl 2: 66-69.

27. Lyritis GP, Paspati I, Karachalios T, Ioakimidis D, Skarantavos G, Lyritis PG. Pain relief from nasal salmon calcitonin in osteoporotic vertebral fractures. A double blind, placebo controlled clinical study. Acta Orthop Scand. 1997;275(Suppl):112-114.

28. Lyritis GP, Ioannidis GV, Karachalios T, et al. Analgesic effect of salmon calcitonin suppositories in patients with acute pain due to recent osteoporotic vertebral crush fractures: a prospective double-blind, randomised, placebo-controlled clinical study. Clin J Pain. 1999;15: 284-289.

29. Sinaki M, Lynn SG. Reducing the risk of falls through proprioceptive dynamic posture training in osteoporotic women with kyphotic posturing: a randomized pilot study. Am J Phys Med Rehabil. 2002; 81:241-246.
30. Pfeifer M, Begerow B, Minne HW. Effects of a new spinal orthosis on posture, trunk strength, and quality of life in women with postmenopausal osteoporosis: a randomized trial. Am J Phys Med Rehabil. 2004; 83:177-186.

31. Hildebrandt HD, Vogt L. Der "Osteoporosebody" - eine multifunktionale Orthese. Orthopädie-Technik. 2002;53:90-96.

32. Vogt L, Hübscher M, Brettmann K, Banzer W, Fink M. Postural correction by osteoporosis orthosis (Osteo-med): a randomized, placebo-controlled trial. Prosthet Orthot Int. 2008;32:103-110.

33. Kaplan RS, Sinaki M, Hameister MD. Effect of back supports on back strength in patients with osteoporosis: a pilot study. Mayo Clin Proc. 1996;71:235-241.

34. Dionyssiotis Y, Michas G, Galanos A, Thoma S, Lyritis GP. A perspective study of spinal orthosis in postmenopausal women. Osteoporos Int. 2009;20 Suppl 1:S23-S176.

35. Bonner FJ Jr, Sinaki M, Grabois M, et al. Health professional's guide to rehabilitation of the patient with osteoporosis. Osteoporos Int. 2003;14 Supp1 2:S1-S22.

36. Bassey EJ. Exercise for prevention of osteoporotic fracture. Age Ageing. 2001;30 Suppl 4:29-31.

37. Sinaki M, Mikkelsen BA. Postmenopausal spinal osteoporosis: flexion versus extension exercises. Arch Phys Med Rehabil. 1984;65: 593-596.

38. Rapado A. General management of vertebral fractures. Bone. 1996; 18:S191-S196.

39. Sinaki M. Musculoskeletal rehabilitation. In: Riggs BL, Melton LJ, editors. Osteoporosis: Etiology, Diagnosis, and Management. 2nd ed. Philadelphia: Lippincott-Raven; 1995:435-473.

40. Ahn DK, Lee S, Choi DJ, et al. Mechanical properties of blood-mixed polymethylmetacrylate in percutaneous vertebroplasty. Asian Spine $J$. 2009;3:45-52.

41. Nakamo M, Hirano N, Matsuura K, et al. Percutaneous transpedicular vertebroplasty with calcium phosphate cement in the treatment of osteoporotic vertebral compression and burst fractures. J Neurosurg. 2003;97 Suppl 3:287-293.

42. Lee BJ, Lee SR, Yoo TY. Paraplegia as a complication of percutaneous vertebroplasty with polymethylmethacrylate: a case report. Spine. 2002; 27:E419-E422.

43. Uppin AA, Hirsch JA, Centenera LV, Pfiefer BA, Pazianos AG, Choi IS. Occurrence of new vertebral body fracture after perculaneous vertebroplasty in patients with osteoporosis. J Radiology. 2003;226: 119-124.

44. Kallmes DF, Comstock BA, Heagerty PJ, et al. A randomized trial of vertebroplasty for osteoporotic spinal fractures. N Engl J Med. 2009; 361:569-579.

45. Buchbinder R, Osborne RH, Ebeling PR, et al. A randomized trial of vertebroplasty for painful osteoporotic vertebral fractures. $N$ Engl $J$ Med. 2009;361:557-568.

46. Wardlaw D, Cummings SR, Van Meirhaeghe J, et al. Efficacy and safety of balloon kyphoplasty compared with non-surgical care for vertebral compression fracture (FREE): a randomised controlled trial. Lancet. 2009;373:1016-1024.
International Journal of General Medicine

\section{Publish your work in this journal}

The International Journal of General Medicine is an international, peer-reviewed open-access journal that focuses on general and internal medicine, pathogenesis, epidemiology, diagnosis, monitoring and treatment protocols. The journal is characterized by the rapid reporting of reviews, original research and clinical studies across all disease areas.

\section{Dovepress}

A key focus is the elucidation of disease processes and management protocols resulting in improved outcomes for the patient. The manuscript management system is completely online and includes a very quick and fair peer-review system. Visit http://www.dovepress.com/ testimonials.php to read real quotes from published authors. 